\title{
4.4 Analysis of the influence in loss of coolant accident on fuel rod state
}

The scope of the data experimentally obtained by research the behaviour and properties of water water energy reactor (WWER) type fuel claddings from $\mathrm{Zr} 1 \% \mathrm{Nb}$ alloy under loading conditions simulating the stage of core flooding with water in loss of coolant accident (LOCA) suffices to judge the character and numerical value of criterional parameters of the embrittlement criterion in terms of the cladding stability upon flooding and subsequent implementation of fuel assembly (FA) unloading and transportation. Accidents are considered involving loss of coolant by primary circuit which are characterized by conditions of degraded heat transfer from fuels. During accidents loss of tightness by fuel rod cladding is tolerable, however, in this case, the cooling of a distorted fuel rod and the dismantling (unloading) of the core after an accident have to be feasible.

Keywords: fuel rod, heat resistance, ZR1\%NB alloy, oxidation, deformation, mechanical properties.

\section{INTRODUCTION}

The most important element of reactor plant (RP) safety validation is analysis of behaviour of nuclear fuel (fuel assemblies, fuel rods) in design basis (postulated) accidents.

The objective of the analysis is to validate the fulfillment of safety requirements placed on fuel rod condition in design basis accidents.

A design basis accident is the one for which the design defines initial events and final states as well as contemplates safety systems that with the account for a single failure of safety systems or a single staff error, independent of an initial event, provide for the limitation of its consequences via limits established for accidents of this type [307, 308].

Accidents are considered involving loss of coolant by primary circuit which are characterized by conditions of degraded heat transfer from fuels. Under these conditions, the temperature of fuel rods (fuel and/or cladding) rises compared to that under normal operating conditions. During accidents loss of tightness by fuel rod 
cladding is tolerable, however, in this case, the cooling of a distorted fuel rod and the dismantling (unloading) of the core after an accident have to be feasible.

Limitations placed on specific physical parameters that characterize the fuel rods state in a design basis accident are called safety criteria.

The conclusions on the fulfillment of the criteria are drawn based on the results of design analyses of fuel rod behaviour in design basis accidents using the RAPTA-5 code.

The paper contains the results of computer check-up of fulfilling (not exceeding) safety criteria in design basis accidents involving loss of primary circuit coolant of the large break LOCA (LB LOCA) type using RAPTA-5 code.

\section{Procedure of design modelling fuel rod behaviour in accident}

Estimation of fuel rod state during an accident and determination of criterional parameters are performed via design modelling using the computer code RAPTA-5 $[309,314,315]$.

The RAPTA-5 code is designed to calculate thermomechanical and corrosion behaviour of fuel rods of water cooled power reactors in design basis accidents proceeding from poor heat transfer in a core or quick power changes.

The RAPTA-5 code uses the procedure of coupled solution of unsteady thermomechanical and corrosion problems as applied to a fuel rod; it comprises the following models:

- model of fuel rod initial state at the early moment of an accident with due account for burn-up,

- two-dimensional unsteady heat transfer in a fuel rod,

- parameters of mixed gas state within a cladding,

- model of fuel rod stress-strained state taking into account thermoelastic strain of fuel, tough-elastic-plastic deformation of a cladding,

- model of cladding depressurization effected by excess internal pressure,

- kinetics of high-temperature cladding oxidation in steam, 
- complex of analytic dependences that describe high-temperature properties of materials in the specified temperature range.

The RAPTA-5 code was verified based on the results of experimental studies into deformation and corrosion behaviour of fuel rod simulators under laboratory conditions as well as the results of integral experiments, carried out in rigs and under reactor conditions and regime simulating temperature-force loading conditions typical of LOCA [315].

The basic computer models put into practice in the RAPTA- 5 code are described in the topical report "Procedure and Results of Computer Modelling Fuel Rod Condition in Accidents with Reactivity Increase (RIA)".

\section{Calculated research of fuel rod behaviour in accident attended with main circulation conduit (MCC) rupture}

Calculated research of fuel rod behaviour in design basis accidents are aimed at demonstrating the fulfillment of the safety criteria [309].

To implement the calculations, use is made of the initial data on the fuel rod loading conditions in design basis accidents. In essence, they represent limiting conditions at the fuel cladding surface (temperature of cladding outer surface and coolant pressure) and data on the fuel heat rate height distribution and its variations in the process of an accident.

The temperature conditions of fuel claddings at a different initial power level in LOCA are determined by inter-related neutron physics and thermal hydraulics calculations. Among other things, the calculations result in determining the maximal temperature of fuel rod claddings and checking up the fulfillment of the acceptance criterion, $\mathrm{T}_{\text {clad }}<T_{\text {clad }}^{\lim }=1200^{\circ} \mathrm{C}$.

The corrosion state of fuel rods is assessed and the fulfillment of the criteria equivalent cladding reacted $(\mathrm{ECR})<E C R_{\text {clad }}^{\lim }=18 \%$ and $\Delta \mathrm{M}\left(\mathrm{Zr} \rightarrow \mathrm{ZrO}_{2}\right)<M_{\mathrm{Zr}}^{\lim }=1 \%$ is checked up basing on the results of the calculations carried out by the RAPTA-5 code. 
The fulfillment of the criterion that limits the quantity of oxidized $\mathrm{Zr}$ in a core is checked up in the following way.

For the thermal hydraulics calculations, the core is presented as several groups of fuel rods (channels) subjected to identical (close) temperature conditions during an accident which is basically determined by the initial power level. The fraction of oxidized $\mathrm{Zr}$ with due account for the thermomechanical behaviour of a fuel rod during an accident and the cladding inner surface oxidation after depressurization is assessed by the RAPTA-5 code for each group of fuel rods. The assessment of the fraction of the steam reacted $\mathrm{Zr}$ in a core is implemented via summing up the fractions of oxidized $\mathrm{Zr}$ in fuel rods of each group multiplied by the weight factor of a particular group - the ratio of the quantity of fuel rods in the particular group to the overall quantity of fuel rods in a core.

As an example, consideration is given to the typical design basis accident attended with a prompt transverse rupture of the main circulation conduit (MCC) diameter equivalent (De) 850 in the diameter at the reactor inlet. The accident of this type is regarded to be the maximum design basis one (MDBA).

The initial data on variations in fuel heat rate, coolant pressure and temperatures of fuel cladding outer surfaces during the accident were specified basing on the results of thermohydraulic calculations (Figs. 1, 2).

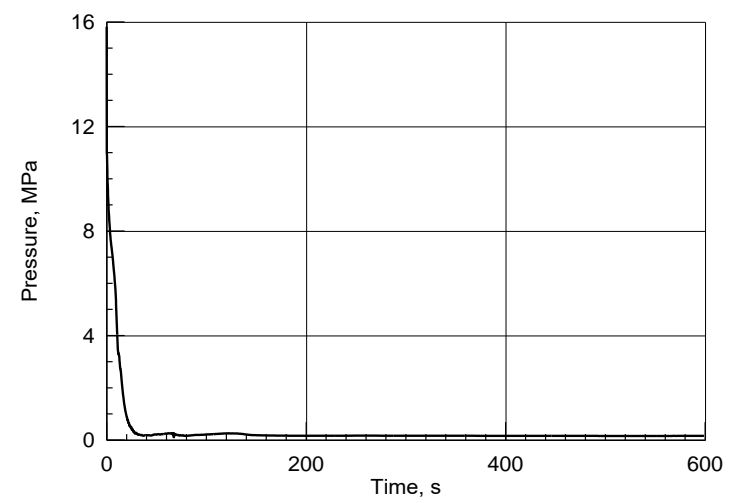

Fig. 1. Rupture of MCC. Variation in coolant pressure.

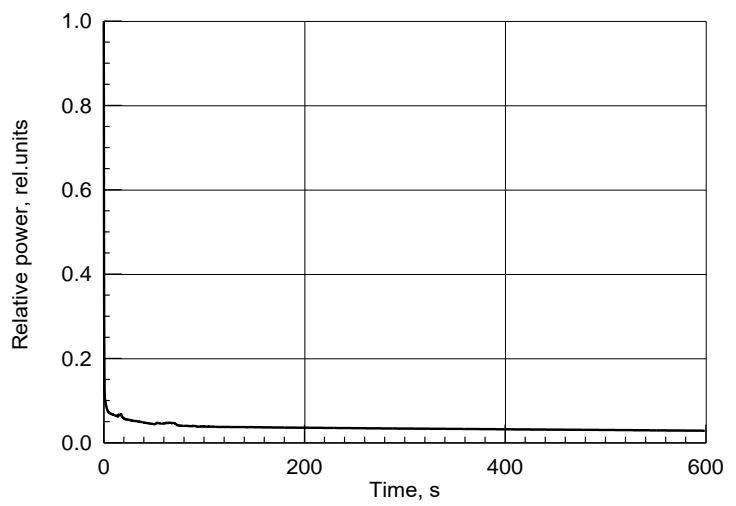

Fig. 2. Rupture of MCC. Variation in relative power.

Two versions are considered pertaining to the distribution of heat rate along the core height $\mathrm{k}_{\mathrm{z}}$ (Table 1). Version 1 corresponds to the beginning of the annual cycle, and Version 2 refers to the end of the annual cycle. 
Table 1.

Core Height Distribution of Heat Rate Non-Uniformity Coefficient $\left(\mathrm{k}_{\mathrm{z}}\right)$

\begin{tabular}{|c|c|c|c|c|c|c|c|c|c|c|}
\hline $\begin{array}{c}\text { Distance from } \\
\text { core bottom, }\end{array}$ & $\mathbf{5}$ & $\mathbf{1 5}$ & $\mathbf{2 5}$ & $\mathbf{3 5}$ & $\mathbf{4 5}$ & $\mathbf{5 5}$ & $\mathbf{6 5}$ & $\mathbf{7 5}$ & $\mathbf{8 5}$ & $\mathbf{9 5}$ \\
\hline Version $\mathrm{k}_{\mathrm{z}}-1$ & 0.36 & 0.84 & 1.13 & 1.30 & 1.39 & 1.39 & 1.27 & 1.12 & 0.84 & 0.36 \\
\hline Version $\mathrm{k}_{\mathrm{z}}-2$ & 0.71 & 0.99 & 1.01 & 1.01 & 1.02 & 1.04 & 1.08 & 1.15 & 1.10 & 0.89 \\
\hline
\end{tabular}

In the $\mathrm{k}_{\mathrm{z}}-1$ version to implement thermohydraulic calculations, the core was presented as seven channels having different relative power: $\mathrm{k}_{\mathrm{r}}=1.0,1.1,1.2,1.3,1.4$, 1.5 and 1.6. In the $\mathrm{k}_{\mathrm{z}}-2$ version it was presented as three channels: $\mathrm{k}_{\mathrm{r}}=1.0,1.34$ and 1.55. The temperature conditions of different power fuel rod claddings during an accident are illustrated in Figs. 3-12.

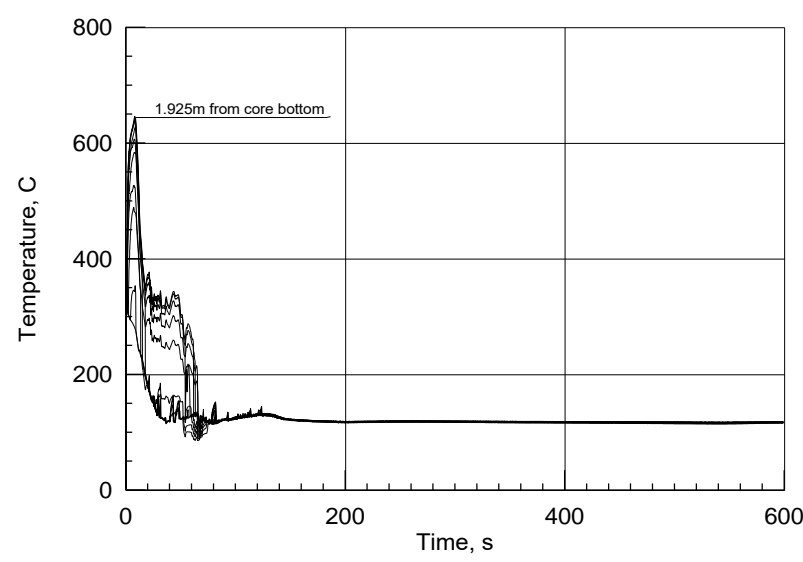

Fig. 3. Rupture of MCC. Temperature of fuel cladding outer surface. Version $k_{z}-1$, $k_{r}=1.0$, maximum linear heat generation rate (LHGR) $240 \mathrm{~W} / \mathrm{cm}$.

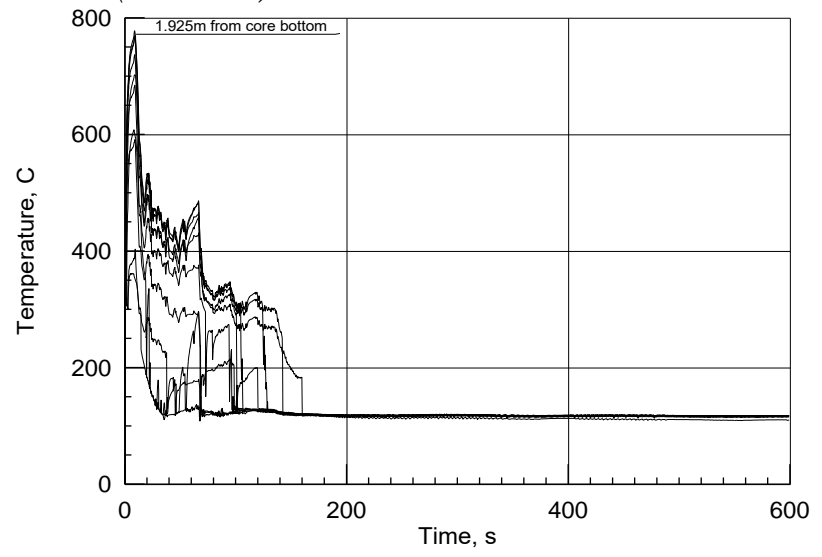

Fig. 4. Rupture of MCC. Temperature of the cladding outer surface. Version $k_{z}-1, k_{r}$ =1.1, maximum LHGR $308 \mathrm{~W} / \mathrm{cm}$.

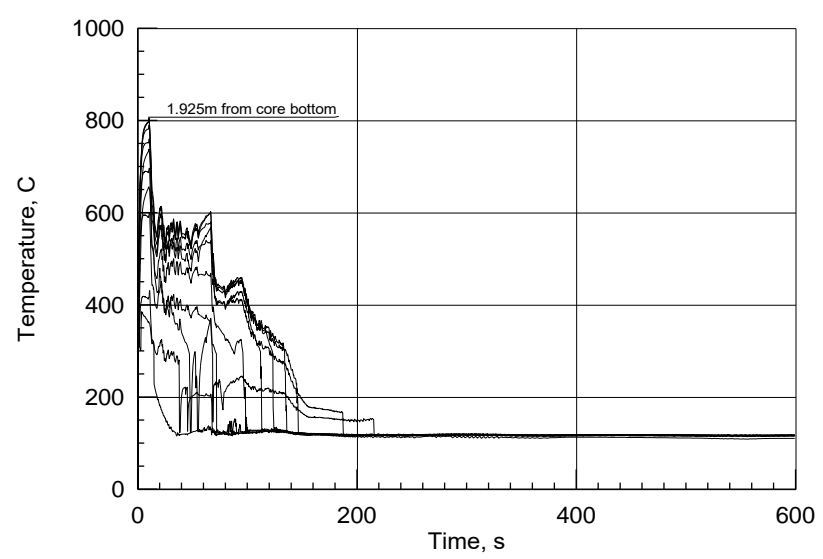

Fig. 5. Rupture of MCC. Temperature of the cladding outer surface. Version $k_{z}-1$, $k_{r}=1.2$, maximum LHGR $336 \mathrm{~W} / \mathrm{cm}$

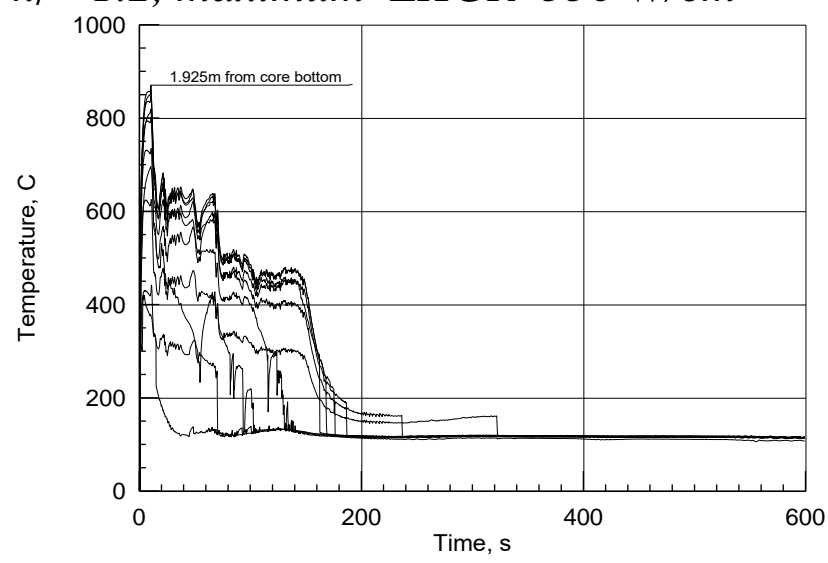

Fig. 6. Rupture of MCC. Temperature of the cladding outer surface. Version $k_{z}-1$, $k_{r}=1.3$, maximum LHGR $364 \mathrm{~W} / \mathrm{cm}$ 


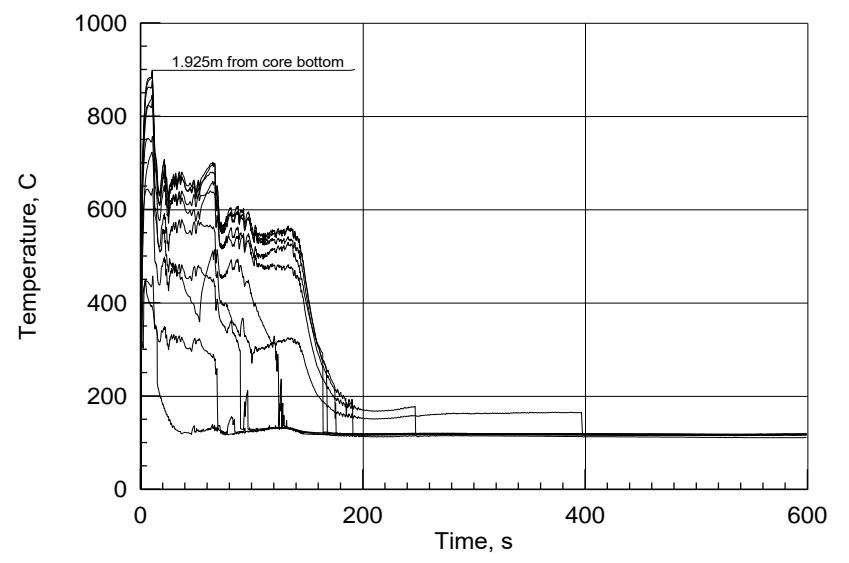

Fig. 7. Rupture of MCC. Temperature of the cladding outer surface. Version $k_{z}-1$, $k_{r}=1.4$, maximum LHGR $392 \mathrm{~W} / \mathrm{cm}$.

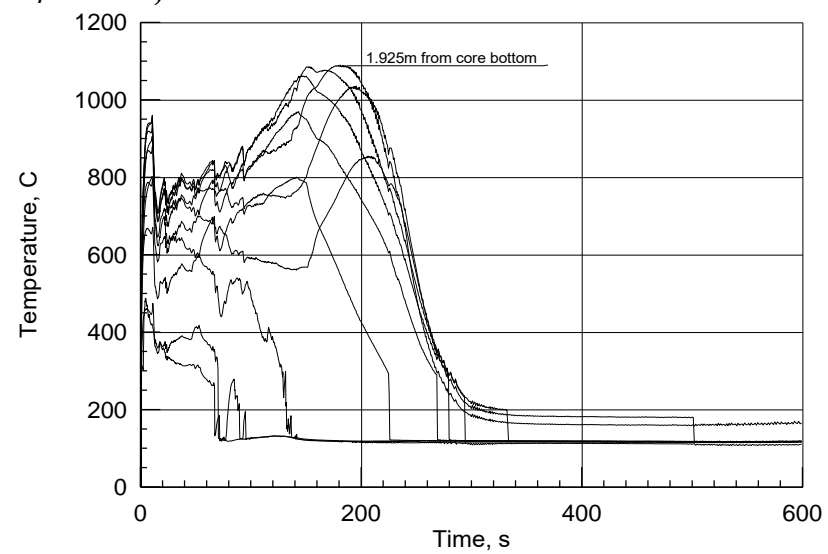

Fig. 8. Rupture of MCC. Temperature of the cladding outer surface. Version $k_{z}-1, k_{r}=1.5$, maximum LHGR $420 \mathrm{~W} / \mathrm{cm}$

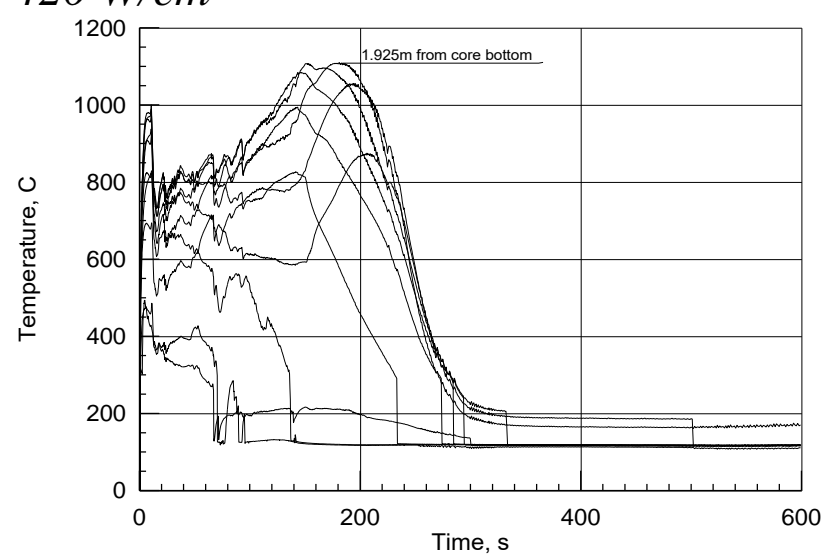

Fig. 9. Rupture of MCC. Temperature of the cladding outer surface. Version $k_{z}-1$, $k_{r}=1.6$, maximum LHGR $448 \mathrm{~W} / \mathrm{cm}$.

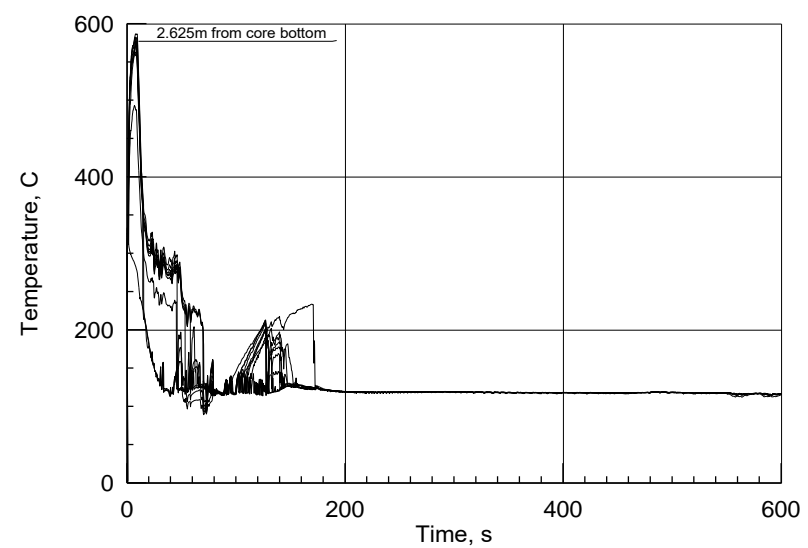

Fig. 10. Rupture of MCC. Temperature of the cladding outer surface. Version $k_{z}-2$, $k_{r}=1.0$, maximum LHGR $198 \mathrm{~W} / \mathrm{cm}$.

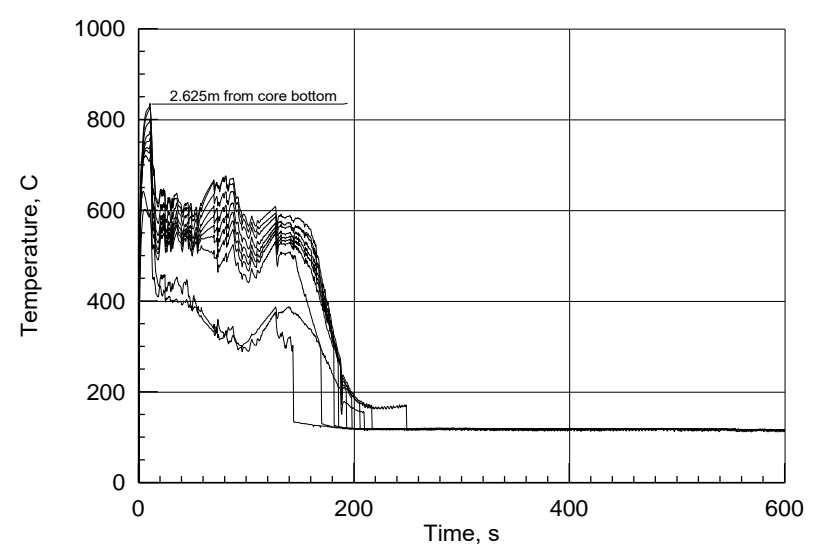

Fig. 11. Rupture of MCC. Temperature of the cladding outer surface. Version $k_{z}-2$, $k_{r}=1.34$, maximum LHGR $307 \mathrm{~W} / \mathrm{cm}$.

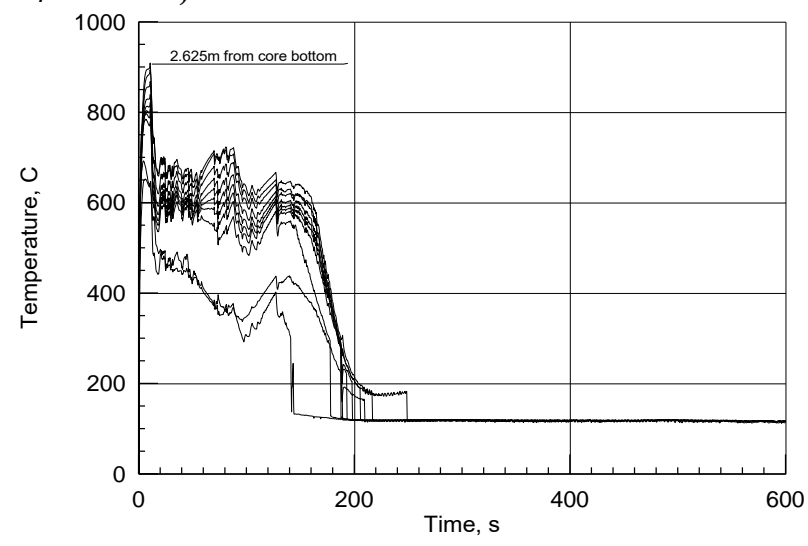

Fig. 12. Rupture of MCC. Temperature of the cladding outer surface. Version $k_{z}-2$, $k_{r}=1.55$, maximum LHGR $360 \mathrm{~W} / \mathrm{cm}$. 
Five different versions of the initial state of fuel rods are considered to be covering the range of the 4-year fuel cycle, it was assumed basing on the history of the highest burn-up fuel rod using the results of the thermophysical calculations:

1) fresh fuel rod having the maximal gap in the tolerable range,

2) early in the $2^{\mathrm{d}}$ year of the cycle (the maximum burn-up of $19 \mathrm{MW} \cdot \mathrm{day} / \mathrm{kgU}$ per pellet),

3) early in the $3^{\mathrm{d}}$ year of the cycle (the maximum burn-up of $38 \mathrm{MW} \cdot$ day $/ \mathrm{kgU}$ per pellet),

4) early in the $4^{\text {th }}$ year of the cycle ( the maximum burn-up of $54 \mathrm{MW} \cdot d a y / k g U$ per pellet),

5) end of the $4^{\text {th }}$ year of the cycle (the maximum burn-up of $68 \mathrm{MW} \bullet$ day $/ \mathrm{kgU}$ per pellet).

Tables 2 and 3 summarize the basic parameters describing the thermomechanical and corrosion behaviour of fuel rods that were determined by RAPTA-5 code calculations [309].

Table 2.

Decisive parameters of fuel rod state in accident attended with main circulation conduit (MCC) rupture $\left(\mathrm{k}_{\mathrm{z}}-1\right)$

\begin{tabular}{|c|c|c|c|c|c|}
\hline \multirow{2}{*}{$\begin{array}{l}\text { No of group } \\
\text { (per power) }\end{array}$} & \multirow{2}{*}{ Parameter } & \multicolumn{4}{|c|}{ № of version of initial fuel rod state } \\
\hline & & 1 & 2 & 3 & 4 \\
\hline \multirow{5}{*}{$\begin{array}{c}1 \\
\left(k_{r}-1.0\right)\end{array}$} & Max. Temperature of fuel, ${ }^{\circ} \mathrm{C}$ & 1059.8 & 1058.4 & 1044.0 & 1112.7 \\
\hline & Max. Temperature of cladding, ${ }^{\circ} \mathrm{C}$ & 647.2 & 647.2 & 647.1 & 647.5 \\
\hline & Hoop logarithmic strain, rel. units & 0.0 & 0.0 & 0.0 & 0.0013 \\
\hline & ECR, \% & 0.023 & 0.023 & 0.023 & 0.023 \\
\hline & $\begin{array}{l}\text { Quantity of oxidized } \mathrm{Zr} \text { in fuel } \\
\text { cladding, } \%\end{array}$ & 0.0126 & 0.0126 & 0.0126 & 0.0126 \\
\hline \multirow{5}{*}{$\begin{array}{c}2 \\
\left(\mathrm{k}_{\mathrm{r}}-1.1\right)\end{array}$} & Max. Temperature of fuel, ${ }^{\circ} \mathrm{C}$ & 1294.2 & 1267.8 & 1271.5 & - \\
\hline & Max. Temperature of cladding, ${ }^{\circ} \mathrm{C}$ & 779.0 & 778.9 & 779.0 & - \\
\hline & Hoop logarithmic strain, rel. units & 0.0008 & 0.0022 & 0.0053 & - \\
\hline & ECR, \% & 0.0952 & 0.0952 & 0.0952 & - \\
\hline & $\begin{array}{l}\text { Quantity of oxidized } \mathrm{Zr} \text { in fuel } \\
\text { cladding, } \%\end{array}$ & 0.0479 & 0.0479 & 0.0480 & - \\
\hline
\end{tabular}




\begin{tabular}{|c|c|c|c|c|c|}
\hline \multirow{5}{*}{$\begin{array}{c}3 \\
\left(k_{r}-1.2\right)\end{array}$} & Max. Temperature of fuel, ${ }^{\circ} \mathrm{C}$ & 1390.5 & 1352.5 & 1366.0 & - \\
\hline & Max. Temperature of cladding, ${ }^{\circ} \mathrm{C}$ & 806.4 & 806.6 & 805.8 & - \\
\hline & Hoop logarithmic strain, rel. units & 0.0043 & 0.0083 & 0.0144 & - \\
\hline & ECR, $\%$ & 0.1315 & 0.1315 & 0.1315 & - \\
\hline & $\begin{array}{l}\text { Quantity of oxidized } \mathrm{Zr} \text { in fuel } \\
\text { cladding, } \%\end{array}$ & 0.0682 & 0.0683 & 0.0685 & - \\
\hline \multirow{5}{*}{$\begin{array}{c}4 \\
\left(k_{r}-1.3\right)\end{array}$} & Max. temperature of fuel, ${ }^{\circ} \mathrm{C}$ & 1484.3 & 1434.0 & 1457.1 & - \\
\hline & Max. temperature of cladding, ${ }^{\circ} \mathrm{C}$ & 870.6 & 870.3 & 870.4 & - \\
\hline & Hoop logarithmic strain, rel. units & 0.0266 & $0.0539 *$ & 0.0966 & - \\
\hline & ECR, $\%$ & 0.2241 & 0.3215 & 0.3695 & - \\
\hline & $\begin{array}{l}\text { Quantity of oxidized } \mathrm{Zr} \text { in fuel } \\
\text { cladding, } \%\end{array}$ & 0.1145 & 0.1591 & 0.1837 & - \\
\hline \multirow{5}{*}{$\begin{array}{c}5 \\
(\mathrm{kr}-1.4)\end{array}$} & Max. temperature of fuel, ${ }^{\circ} \mathrm{C}$ & 1575.8 & 1513.3 & 1546.8 & - \\
\hline & Max. temperature of cladding, ${ }^{\circ} \mathrm{C}$ & 900.1 & 899.0 & 898.8 & - \\
\hline & Hoop logarithmic strain, rel. units & $0.0492 *$ & 0.0819 & 0.1278 & - \\
\hline & ECR, $\%$ & 0.4085 & 0.4468 & 0.5083 & - \\
\hline & $\begin{array}{l}\text { Quantity of oxidized } \mathrm{Zr} \text { in fuel } \\
\text { cladding, } \%\end{array}$ & 0.2004 & 0.2272 & 0.2618 & - \\
\hline \multirow{5}{*}{$\begin{array}{c}6 \\
\left(k_{r}-1.5\right)\end{array}$} & Max. temperature of fuel, ${ }^{\circ} \mathrm{C}$ & 1666.4 & 1591.5 & - & - \\
\hline & Max. temperature of cladding, ${ }^{\circ} \mathrm{C}$ & 1088.9 & 1088.7 & - & - \\
\hline & Hoop logarithmic strain, rel. units & 0.3873 & 0.3867 & - & - \\
\hline & ECR, $\%$ & 4.6607 & 4.6726 & - & - \\
\hline & $\begin{array}{l}\text { Quantity of oxidized } \mathrm{Zr} \text { in fuel } \\
\text { cladding, } \%\end{array}$ & 2.2155 & 2.2499 & - & - \\
\hline \multirow{5}{*}{$\begin{array}{c}7 \\
\left(k_{r}-1.6\right)\end{array}$} & Max. temperature of fuel, ${ }^{\circ} \mathrm{C}$ & 1755.0 & - & - & - \\
\hline & Max. temperature of cladding, ${ }^{\circ} \mathrm{C}$ & 1108.5 & - & - & - \\
\hline & Hoop logarithmic strain, rel. units & 0.3840 & - & - & - \\
\hline & ECR, $\%$ & 5.3408 & - & - & - \\
\hline & $\begin{array}{l}\text { Quantity of oxidized } \mathrm{Zr} \text { in fuel } \\
\text { cladding, } \%\end{array}$ & 2.5911 & - & - & - \\
\hline
\end{tabular}

Table 3.

Decisive parameters of fuel rod state in accident attended with MCC rupture $\mathrm{k}_{\mathrm{z}^{-}}$ 2

\begin{tabular}{|c|c|c|c|c|c|}
\hline \multirow{2}{*}{$\begin{array}{c}\text { No of group } \\
\text { (per power) }\end{array}$} & Parameter & \multicolumn{3}{|c|}{ № of version of initial fuel rod state } \\
\cline { 2 - 5 } & Max. temperature of fuel, ${ }^{\circ} \mathrm{C}$ & $\mathbf{2}$ & $\mathbf{3}$ & $\mathbf{4}$ & $\mathbf{5}$ \\
\hline \multirow{4}{*}{$\begin{array}{c}1 \\
(\mathrm{k}-1.0)\end{array}$} & Max. temperature of cladding, ${ }^{\circ} \mathrm{C}$ & 587.6 & 912.0 & 969.8 & 1047.4 \\
\cline { 2 - 6 } & Hoop logarithmic strain, rel. units & 0.0 & 0.0 & 0.0001 & 0.0033 \\
\cline { 2 - 6 } & ECR, \% & 0.0111 & 0.0111 & 0.0111 & 0.0111 \\
\cline { 2 - 6 } & $\begin{array}{c}\text { Quantity of oxidized Zr in fuel } \\
\text { cladding, \% }\end{array}$ & 0.0087 & 0.0087 & 0.0087 & 0.0087 \\
\hline
\end{tabular}




\begin{tabular}{|c|c|c|c|c|c|}
\hline \multirow{5}{*}{$\begin{array}{c}2 \\
\left(\mathrm{k}_{\mathrm{r}}-1.34\right)\end{array}$} & Max. temperature of fuel, ${ }^{\circ} \mathrm{C}$ & 1265.1 & 1269.5 & 1349.2 & - \\
\hline & Max. temperature of cladding, ${ }^{\circ} \mathrm{C}$ & 834.7 & 833.1 & 833.1 & - \\
\hline & Hoop logarithmic strain, rel. units & $0.0611 *$ & 0.1018 & 0.1327 & - \\
\hline & ECR, \% & 0.2712 & 0.2953 & 0.3081 & - \\
\hline & $\begin{array}{l}\text { Quantity of oxidized } \mathrm{Zr} \text { in fuel } \\
\text { cladding, } \%\end{array}$ & 0.1513 & 0.1670 & 0.1762 & - \\
\hline \multirow{5}{*}{$\begin{array}{c}3 \\
\left(\mathrm{k}_{\mathrm{r}}-1.55\right)\end{array}$} & Max. temperature of fuel, ${ }^{\circ} \mathrm{C}$ & 1416.3 & - & - & - \\
\hline & Max. temperature of cladding, ${ }^{\circ} \mathrm{C}$ & 905.9 & - & - & - \\
\hline & Hoop logarithmic strain, rel. units & 0.1888 & - & - & - \\
\hline & ECR, $\%$ & 0.5956 & - & - & - \\
\hline & $\begin{array}{l}\text { Quantity of oxidized } \mathrm{Zr} \text { in fuel } \\
\text { cladding, } \%\end{array}$ & 0.3531 & - & & \\
\hline
\end{tabular}

For fuel rods of the initial relative power $\mathrm{k}_{\mathrm{r}} \geq 1.3$, the predicted loss of cladding tightness was calculated from the lower estimate of the deformation rupture criterion (Table 2,3) after which the account of the cladding inner surface oxidation began. The calculation of straining continued until rupture using the mean estimate of the deformation criterion to acquire the conservative value of the oxidized $\mathrm{Zr}$ quantity taking into account an increase in the cladding surface area.

To assess the overall quantity of oxidized $\mathrm{Zr}$ in a core, the estimated fractions of oxidized zirconium in fuel rods of each group multiplied by the respective weight factors were summed up. The weight factor for each group is determined as the ratio of the fuel rod quantity per group to the overall quantity of fuel rods per core.

\section{Conclusion}

The representative maximal design limit of a fuel rod damage in terms of oxidation (the embrittlement criterion) covers all together the maximum temperature of the fuel rod cladding and ECR.

The numerical values of the criterional parameters $T_{\text {clad }}^{\lim }=1200^{\circ} \mathrm{C}$ and $E C R_{\text {clad }}^{\lim }=18 \%$ are validated by the data experimentally acquired from studying the kinetics of the $\mathrm{Zr}$ steam reaction and the special thermal shock experiments.

It is demonstrated that the mechanical properties of oxidized claddings subjected to thermal shock (impact elasticity, residual ductility) are adequate for claddings to 
remain stable in flooding and implementing the subsequent activities (fuel assembly discharge and transportation).

In terms of fuel rod claddings, the limitation of hydrogen released as a result of the $\mathrm{Zr}$-steam reaction is provided by meeting the following requirement: the fraction of steam reacted $\mathrm{Zr}$ in a core must not exceed $1 \%$ of its mass in fuel rod claddings.

The criterion of intolerance of fuel melting ensures that the liquid phase of the fuel does not interact with the cladding.

The computer investigations of the thermomechanical and corrosion behaviour of fuel rods in the typical design basis accident (DBA) attended with a prompt transverse rupture of MCC at a reactor inlet evidence the fulfillment of the safety criteria.

It is apparent that the safety criteria placed upon the fuel rod state in design basis accidents of the "uncompensable small break LOCA" type are met. 